\title{
Changes in cerebrospinal fluid and blood plasma levels of IGF-II and its binding proteins in Alzheimer's disease: an observational study
}

\author{
Joakim Hertze ${ }^{1,2^{*}}$, Katarina Nägga ${ }^{1,2}$, Lennart Minthon ${ }^{1,2}$ and Oskar Hansson ${ }^{1,2}$
}

\begin{abstract}
Background: The Insulin-like Growth Factor (IGF)-related system is implicated in neuroregeneration and cell repair, as well as regulating lifespan. IGF-II, one component of this system, has also been found to affect memory functions in a rat model. In this study we explored changes in the IGF-related system in patients with Alzheimer's disease (AD), including changes in IGF-II levels.
\end{abstract}

Methods: We measured blood plasma and cerebrospinal fluid (CSF) levels of IGF-I, IGF-II, IGFBP-2 and IGFBP-3 in 72 healthy controls and 92 patients with AD.

Results: We found significantly lower blood plasma levels of IGF-II and IGFBP-3 in patients with AD, compared with controls. The levels of IGF-II and IGFBP-2 were significantly elevated in the CSF from patients with AD. We also found correlations between established CSF biomarkers for AD (tau and P-tau) and components of the IGF system.

Conclusions: CSF and blood plasma levels of IGF-II and some of its binding proteins are changed in patients with AD. Further investigation into this area may unravel important clues to the nature of this disease.

Keywords: Alzheimer Disease, Dementia, Cerebrospinal fluid, Blood plasma, IGF-I, IGF-II, IGFBP-2, IGFBP-3, Insulin

\section{Background}

Alzheimer's disease (AD), the most common cause of dementia $[1,2]$, is a heterogeneous condition. Neuropathological hallmarks of the disease include senile plaques containing $\beta$-amyloid (A $\beta 42$ ), and neurofibrillary tangles (NTFs), containing hyper-phosphorylated tau (P-tau). The so-called amyloid hypothesis proposes that skewed amyloid homeostasis promotes the accumulation of $\mathrm{A} \beta 42$ in the brain. This is commonly thought to represent the earliest event in the development of AD [3].

The insulin-like growth factor (IGF)-related system is comprised of two ligands, IGF-I and IGF-II, their binding proteins and their cell-surface receptors [4]. Some authors also include insulin and the insulin receptor (IR) with this system [5]. IGF-I is mainly synthesized in the liver as a response to growth hormone $(\mathrm{GH})$, but also in other tissues-including neurons-in an autocrine/paracrine

\footnotetext{
* Correspondence: joakim.hertze@med.lu.se

${ }^{1}$ Clinical Memory Research Unit, Department of Clinical Sciences, Lund University, Malmö, Sweden

${ }^{2}$ Memory Clinic, Skåne University Hospital, Lund and Malmö, Sweden
}

manner, seemingly independent of GH [2]. IGF-II is less well understood than IGF-I. It is expressed in the brain during fetal development, but it is also the most abundantly expressed IGF in the adult central nervous system (CNS) [6], with its highest relative concentration in the hippocampus [7]. Both IGF-I and IGF-II are potent growth-promoting and neuroprotective factors in the human nervous system $[7,8]$.

Three types of cell surface receptors bind the ligands of the IGF-related system. IGF-IR binds IGF-I with high affinity, but also IGF-II and insulin with much lower affinity [9]. IGF-IIR binds IGF-II with high affinity, but also IGF-I with much lower affinity [6,9]. Both IGF-I and IGF-II also bind to the IR [9]. IGF-IR and IR are both tyrosine kinase receptors, while IGF-IIR is identical to the cation-independent mannose-6-phosphate receptor. The structurally distinct IGF-IIR not only transmits a signal when IGF-II binds, but also targets the ligand for endocytosis-mediated lysosomal degradation [10].

In biological fluids, IGF-I and IGF-II are normally bound to carrier proteins, IGFBPs, which extend their 
half-life and modulate their availability and bioactivity. So far, a family of six binding proteins, IGFBP-1 through 6 , has been characterized. Of these six proteins, IGFBP-3 is the most abundant one in the bloodstream, while IGFBP-2 is the most abundant one in the intrathecal space $[11,12]$. IGFBP-2 is detectable throughout the brain, but particularly so in regions undergoing continuous remodelling, such as the olfactory bulb, the cerebellum and the hippocampus [6,11]. IGFBP-2 binds IGF-II with a moderate preferential affinity over IGF-I [13]. The expression of IGFBP-2 correlates with and complements that of IGF-II [6].

Humans, as well as most mammals, experience a cognitive decline in old age. This was long thought to be caused by neuronal cell loss, but has been found to be more related to impaired neuronal plasticity [14]. As we grow older, levels of GH, IGF-I and IGF-II fall progressively $[15,16]$ and an association between circulating levels of IGF-I and cognitive decline has been described [17-19]. Moreover, reduced mRNA expression of IGFIR, IGF-IIR and IR, in the brain of patients with AD has been reported, with expression levels decreasing as the disease progresses [20,21]. In a recent study by Chen et al., injecting recombinant IGF-II into the hippocampus greatly enhanced memory retention and reduced forgetting in a rat model. Interestingly, this effect seems to be mediated by the IGF-IIR receptor [7], not the more extensively explored IGF-IR. Furthermore, galantamine, an acetylcholinesterase-inhibiting drug used to ameliorate the symptoms of $\mathrm{AD}$, was shown to increase hippocampal levels of IGF-II in mice [22].

There is also evidence linking the IGF-related system to the clearance of $\beta$-amyloid. Reduced IGF signaling protects against behavioral deficits, neuroinflammation and neuronal loss in a transgenic mouse model of $\mathrm{AD}$ and this effect was found to be associated with the sequestration of soluble, toxic oligomers [23]. Similar results were found in a different study [24]. On the other hand, elevated serum levels of IGF-I seems to increase the clearance of $A \beta 42$ in the brain of mice [25] and IGFI has also been shown to protect brain cells from $A \beta 42-$ induced neuronal cell death [26-28].

In light of evidence linking the IGF-related system to cognition, as well as several changes observed in $\mathrm{AD}$, we hypothesized that alterations in this system might contribute to the pathological mechanisms underlying this form of dementia. While the role of IGF-I has been explored to some degree in patients with $\mathrm{AD}$, less is known about IGF-II in this context. Indeed, to the best of our knowledge, only one previous study has investigated changes in CSF and blood plasma levels of IGF-II in humans with $\mathrm{AD}$-related pathology. In the present study, we investigated the levels of both IGF-I and IGFII, as well as levels of IGFBP-2 and IGFBP-3 in CSF and blood plasma in cognitively healthy controls and in patients with a clinical diagnosis of AD.

\section{Methods}

\section{Study participants}

This study was performed at the Memory Clinic of Skåne University Hospital in Malmö, Sweden. CSF and blood plasma samples were obtained from 72 cognitively healthy volunteers and from 92 patients diagnosed with $\mathrm{AD}$. The healthy participants were recruited in the same city. To be included, they were not allowed to have any cognitive complaints or any significant neurological or psychiatric illness and they needed to have a wellpreserved general cognitive functioning. All controls were assessed with either magnetic resonance imaging (MRI) or computed tomography $(\mathrm{CT})$ of the brain. A careful clinical interview, together with an assessment of global function (Mini-Mental State Examination, MMSE), delayed recall (Alzheimer's Disease Assessment Scale Cognitive Subscale, ADAS Cog, item 3), attention (a quick test of cognitive speed, AQT) and visuospatial and executive function (cube-drawing test and clock test), was done to rule out mild cognitive impairment. Patients diagnosed with AD met the DSM-IIIR criteria for dementia [29] and the criteria for probable $\mathrm{AD}$, as defined by NINCDS-ADRDA [30]. All subjects were assessed by medical doctors with extensive experience in cognitive disorders. For all patients and controls, blood plasma and CSF samples were obtained at some point between 8 a.m. and 12 a.m. White matter lesions (WMLs) were quantified in individuals who had undergone CT scans of their brains, using the ARMMC (Age-related White Matter lesions) scale [31]. All controls provided written informed consent to participate in this study. Due to the retrospective study design, written consent was not possible from the $\mathrm{AD}$ patients. Data and CSF from those patients were collected as part of a clinical routine investigation and in conjunction with this they gave oral informed consent for future use of their banked CSF samples for research. This fact was documented in the patients' medical records. All patients were later on instructed to withdraw their permission, had they changed their minds, as instructed in local press advertisements. The design of this study has been approved by the Local Ethics Committee of Lund University, Sweden and the study procedure was conducted in accordance with the Helsinki Declaration.

\section{CSF samples and IGF measurements}

CSF was collected in polypropylene tubes and mixed gently to avoid gradient effects. All samples were centrifuged within $30 \mathrm{~min}$ at $+4^{\circ} \mathrm{C}$ at $2000 \mathrm{~g}$ for ten minutes to remove cells and debris. Samples were stored in aliquots at $-80^{\circ} \mathrm{C}$ pending biochemical analysis. The procedure followed The Alzheimer's Association Flow Chart for LP 
and CSF sample processing [32]. Commercial kits from Mediagnost GmbH (Reutlingen, Germany), were used for all analyses of the IGF system. Levels of IGF-II and IGFBP-2 were analyzed using a sandwich enzyme-linked immunosorbent assay (ELISA), while radioimmunoassays (RIAs) were used for IGF-I and IGFBP-3. Spike analyses were performed and test subject samples were diluted in accordance with the kits' manuals. The mean correctional values (CVs) for IGF-I, IGF-II, IGFBP-2 and IGFBP-3 in blood plasma was $8.6 \%$ (standard deviation, $\mathrm{SD}=6.4 \%), 3.1 \%(\mathrm{SD}=3.2 \%), 2.4 \%(\mathrm{SD}=2.3 \%)$ and $4.1 \%$ $(\mathrm{SD}=3.2 \%)$ respectively. The CV in CSF for IGF-I. IGF-II, IGFBP-2 and IGFBP-3 was $10.7 \%(\mathrm{SD}=9.8 \%), 1.7 \%$ $(\mathrm{SD}=1.7 \%), 2.5 \% \quad(\mathrm{SD}=2.7 \%)$ and $3.7 \% \quad(\mathrm{SD}=3.5 \%)$ respectively.

The levels of $\beta$-amyloid a $_{1-42}(\mathrm{~A} \beta 42)$, tau and tau phosphorylated at Thr181 (P-tau) were determined using xMAP technology as described [33].

\section{Statistical analysis}

The statistical analyses were made with IBM SPSS for Macintosh, version 19.0.0 (IBM Corp., Armonk, NY, USA). Mann-Whitney nonparametric $U$ tests were used for comparing age and MMSE scores between the two groups, while a Pearson's $\chi^{2}$ test was used for comparing gender distribution and vascular risk factors. To adjust for the potentially confounding effects of age, continuous variables were log-transformed to obtain a normal distribution, before a general linear model analysis of covariance (ANCOVA) was performed for each biomarker, with age included as a co-variate in the analyses. We then performed ANCOVA analyses for each biomarker, with both age and body mass index (BMI) included as co-variates. Even though the gender distribution did not differ in a statistically significant way between the two groups, we also performed an ANCOVA analyses for each biomarker, with age, BMI and gender included as co-variates. Age, gender, and IGF and IGFBP levels were available in all cases, but BMI was only available in 47 controls and 88 patients with AD. Because of the high CVs for the analyses of IGF-I, we also excluded cases with a CV $>20 \%$ in a separate analysis. Spearman's correlation coefficient $r_{s}$ was determined for bivariate correlation analyses.

\section{Results}

The demographic data and measurements of IGF-I, IGFII, IGFBP-2 and IGFBP-3 levels in blood plasma and CSF are shown in Table 1 . Whereas no statistically significant difference was found in gender distribution, the patients with $\mathrm{AD}$ were slightly older $(\mathrm{p}<0.05)$ than the controls (Table 1).

In blood plasma, levels of IGF-II were significantly decreased in patients with $\mathrm{AD}(\mathrm{p}<0.005)$, even after
Table 1 Demographics, vascular risk factors and IGF levels in plasma and CSF

\begin{tabular}{|c|c|c|}
\hline & Controls $(n=72)$ & $A D(n=92)$ \\
\hline Gender (male/female) & $16 / 56$ & $32 / 60$ \\
\hline Age (years) & $75 \pm 7$ & $76 \pm 7^{\mathrm{a}}$ \\
\hline MMSE at baseline & $29 \pm 2$ & $19 \pm 4^{\mathrm{b}}$ \\
\hline Body Mass Index (BMI) & $27 \pm 5$ & $24 \pm 4^{b}$ \\
\hline Arterial hypertension (yes/no) & $19 / 53$ & $27 / 65$ \\
\hline Diabetes mellitus (yes/no) & $6 / 66$ & $9 / 83$ \\
\hline Hyperlipidemia (yes/no) & $18 / 54$ & $14 / 77$ \\
\hline Atherosclerotic disease (yes/no) & $9 / 61$ & $13 / 78$ \\
\hline Previous stroke (yes/no) & $0 / 72$ & $0 / 92$ \\
\hline CSF tau & $95 \pm 50$ & $173 \pm 97^{b}$ \\
\hline CSF P-tau & $31 \pm 18$ & $130 \pm 74^{b}$ \\
\hline CSF Aß42 & $260 \pm 77$ & $157 \pm 41^{b}$ \\
\hline CSF IGF-I & $0.60 \pm 0.20$ & $0.62 \pm 0.25$ \\
\hline CSF IGF-II & $41 \pm 7$ & $45 \pm 8^{\mathrm{a}}$ \\
\hline CSF IGFBP-2 & $122 \pm 23$ & $136 \pm 27^{\mathrm{a}}$ \\
\hline CSF IGFBP-3 & $18 \pm 6$ & $21 \pm 8$ \\
\hline CSF IGF-I/IGFBP-3 & $0.035 \pm 0.009$ & $0.032 \pm 0.009$ \\
\hline Plasma IGF-I & $99 \pm 38$ & $92 \pm 39$ \\
\hline Plasma IGF-II & $680 \pm 105$ & $619 \pm 114^{b}$ \\
\hline Plasma IGFBP-2 & $483 \pm 234$ & $632 \pm 354^{b}$ \\
\hline Plasma IGFBP-3 & $2.3 \pm 0.65$ & $2.0 \pm 0.57^{a}$ \\
\hline Plasma IGF-I/IGFBP-3 & $44 \pm 19$ & $46 \pm 20$ \\
\hline
\end{tabular}

Data are presented as means \pm standard deviations, or counts. CSF and blood plasma biomarker levels are given in $\mathrm{ng} / \mathrm{ml}$, except for plasma IGFBP-3, which is given in $\mu \mathrm{g} / \mathrm{ml}$. CSF tau, CSF p-Tau and CSF A 42 are given in $\mathrm{ng} / \mathrm{L}$. The $\mathrm{BMl}$, given in $\mathrm{kg} / \mathrm{m}^{2}$, was available for 88 patients with $A D$ and 47 controls. ${ }^{a} \mathrm{p}<0.05$ vs. controls; ${ }^{b} p<0.005$ vs. controls. Data were not available for all individuals regarding hyperlipidemia and atherosclerotic disease. In this study, previous myocardial infarction, angina pectoris or stenosis of carotid arteries were used as markers for atherosclerotic disease. For the purpose of this table, an ANCOVA analysis adjusted for age was used for all biomarkers in blood plasma and CSF.

adjusting for age (Table 1; Figure 1). The level of the main IGF-binding protein in plasma (i.e., IGFBP-3) was also reduced $(\mathrm{p}<0.05)$, but the levels of IGFBP-2 were significantly higher $(\mathrm{p}<0.005)$. In CSF, levels of IGF-II and the main IGF-binding protein in CSF (i.e. IGFBP-2) were significantly higher in patients with $\mathrm{AD}$, even after adjusting for age in statistical analyses $(\mathrm{p}<0.05)$ (Table 1 ; Figure 2).

The results presented above remained fairly unchanged when adjusting for both age and BMI. In CSF, the difference in levels of IGF-II, IGFBP-2 and IGFBP-3 reached statistical significance $(\mathrm{p}<0.05)$. However, the level of IGF-I in CSF still did not differ between the two groups. In blood plasma, differences in levels of IGF-II and IGFBP-3 reached statistical significance $(\mathrm{p}<0.005)$. Levels of IGF-I and IGFBP-2 in blood plasma did not differ between the two groups. 

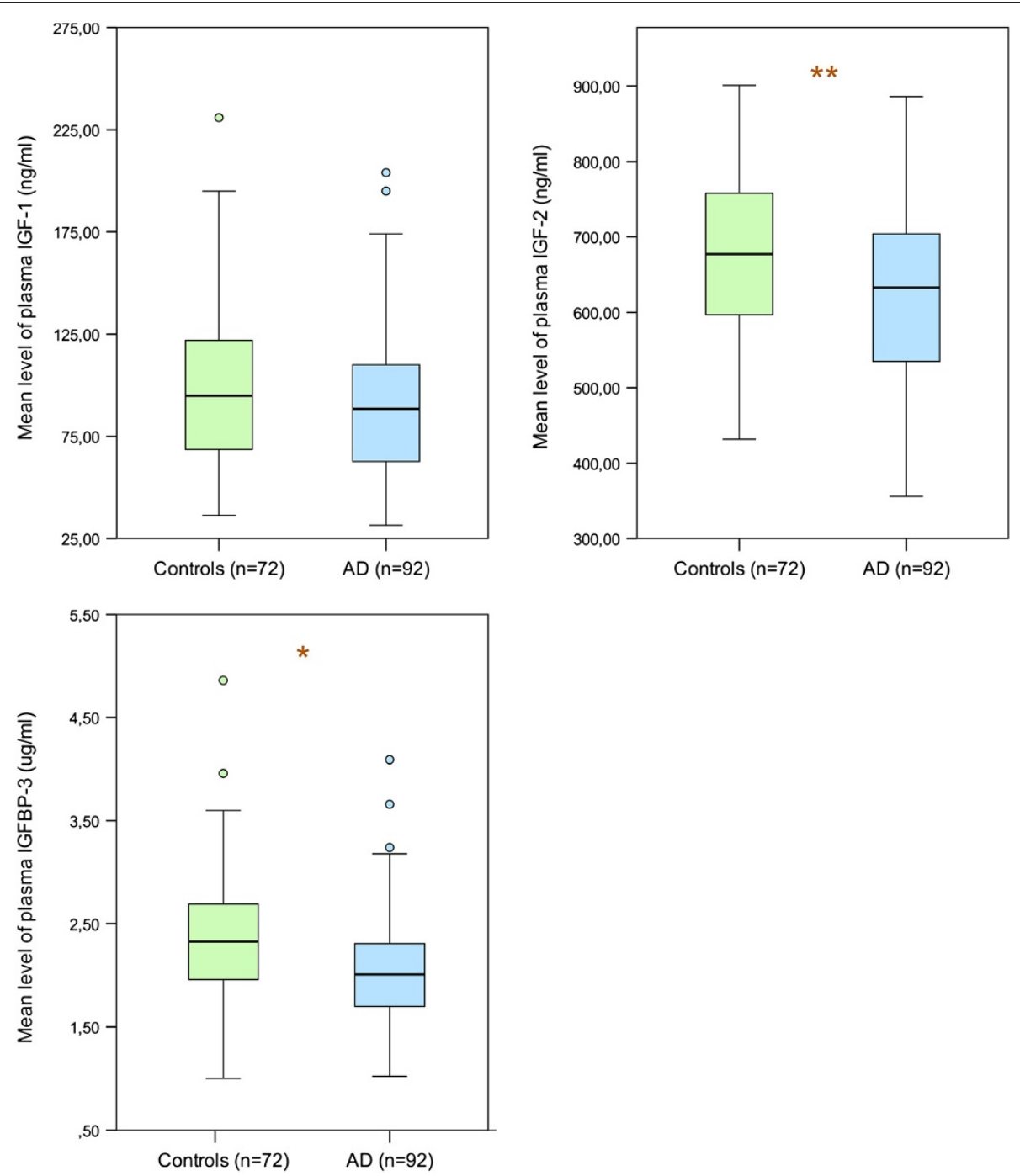

Figure 1 Concentrations of IGF-I, IGF-II and IGFBP-3 (the most abundant carrier in the bloodstream) in plasma. The lower, upper and middle lines correspond to the $25^{\text {th }}$ percentile, $75^{\text {th }}$ percentile and median, respectively. The whiskers at the top and bottom extend between the $95^{\text {th }}$ and the $5^{\text {th }}$ percentiles. The circles represent outliers. ${ }^{*} p<0.05$ and ${ }^{* *} p<0.005$.

When adjusting for age, BMI and gender (even though gender did not differ between patients and controls in a significant way), only IGF-II and IGFBP-3 in blood plasma reached statistical significance $(\mathrm{p}<0.05)$. In CSF samples, IGF-II and IGFBP-2 very nearly reached a significance level of $\mathrm{p}=0.05$ (data not shown). It is possible that this arose from a loss of statistical power due to small sample sizes. Nevertheless, we also analyzed differences between patients with $\mathrm{AD}$ and controls in men and women separately, still adjusting for age and BMI. While the sample sizes were then even smaller, it is interesting to note that while we found no differences among the women, men had significantly reduced levels of IGF-II and IGFBP-3 in blood plasma ( $\mathrm{p}<0.05$ and $\mathrm{p}<0.001$, respectively).

In light of evidence linking the drug galantamine to an increase in hippocampal IGF-II mRNA levels in a mouse model [22], we also excluded patients with AD who had already started treatment with any type of acetylcholinesterase inhibitor at the time of collection of CSF (10 individuals). This did not change our findings in any significant way (data not shown).

Levels of IGF-I in blood plasma or CSF did not differ significantly between the patients with $\mathrm{AD}$ and controls. Because of the high CV values for IGF-I, we also excluded cases with CV values above $20 \%$ for IGF-I in blood plasma or CSF, but differences between the two groups still did not reach a statistical significance (data not shown).

\section{Correlations}

The correlations between biomarkers in CSF and MMSE in all study participants are shown in Table 2. 

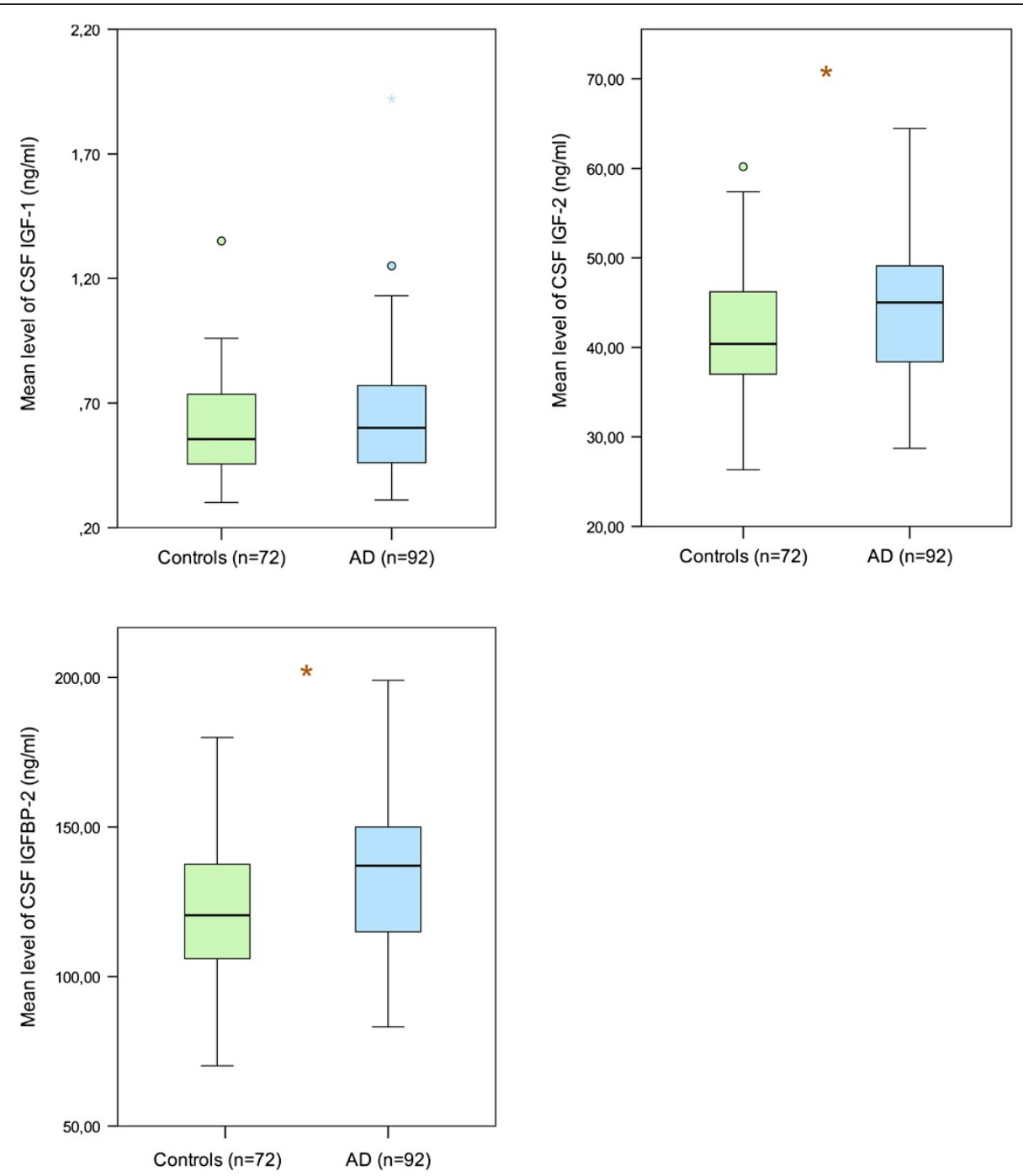

Figure 2 Concentrations of IGF-I, IGF-II and IGFBP-2 (the most abundant carrier in the intrathecal space) in CSF. The lower, upper and middle lines correspond to the $25^{\text {th }}$ percentile, $75^{\text {th }}$ percentile and median, respectively. The whiskers at the top and bottom extend between the $95^{\text {th }}$ and the $5^{\text {th }}$ percentiles. The circles represent outliers. ${ }^{*} p<0.05$.

Table 2 Correlations between biomarkers in CSF and MMSE in patients with AD and controls combined

\begin{tabular}{lllll}
\hline & CSF A $\mathbf{3 4 2}$ & CSF Tau & CSF P-Tau & MMSE \\
\hline CSF IGF-I & $0.253^{\mathrm{a}}$ & 0.191 & 0.116 & -0.005 \\
CSF IGF-II & 0.058 & 0.161 & 0.155 & $-0.178^{\mathrm{a}}$ \\
CSF IGFBP-2 & 0.034 & $0.463^{\mathrm{b}}$ & $0.374^{\mathrm{b}}$ & $-0.250^{\mathrm{b}}$ \\
CSF IGFBP-3 & 0.060 & $0.308^{\mathrm{b}}$ & $0.266^{\mathrm{a}}$ & -0.143 \\
MMSE & $0.374^{\mathrm{b}}$ & $-0.442^{\mathrm{b}}$ & $-0.567^{\mathrm{b}}$ & 1.000 \\
\hline
\end{tabular}

Numbers are Spearman correlation coefficients $\left(r_{s}\right) .{ }^{a} p<0.05 ;{ }^{b} p<0.005$. Abbreviations: CSF cerebrospinal fluid, IGF insulin growth factor, IGFBP insulin growth factor binding protein, MMSE Mini-Mental State Examination.
In patients with $\mathrm{AD}$, the CSF levels of tau and P-tau correlated positively with CSF levels of IGFBP-2 ( $\mathrm{p}<0.05$, $r_{s}=0.380$ and 0.398 , respectively). Levels of P-tau also correlated positively with the CSF levels of IGF-I $(\mathrm{p}<0.05$, $\left.r_{s}=0.253\right)$ and CSF levels of IGFBP-3 $\left(p<0.005, r_{s}=0.322\right)$ (Table 3 ). In healthy controls there was a positive correlation between tau and all analyzed IGF components in CSF (Table 4).

We did not find any significant correlations between CSF and blood plasma levels in any of the four IGFsystem components analyzed (data not shown. Further, we found no correlations between MMSE scores and CSF or blood plasma levels of any of the four IGFsystem components in the AD group (Table 3 ). 
Table 3 Correlations between biomarkers in CSF and MMSE in patients with AD

\begin{tabular}{lllll}
\hline & CSF A $\beta$ 42 & CSF Tau & CSF P-Tau & MMSE \\
\hline CSF IGF-I & 0.220 & 0.146 & $0.253^{\mathrm{a}}$ & 0.096 \\
CSF IGF-II & 0.155 & 0.050 & 0.183 & 0.034 \\
CSF IGFBP-2 & 0.177 & $0.380^{\mathrm{b}}$ & $0.398^{\mathrm{b}}$ & -0.075 \\
CSF IGFBP-3 & 0.294 & 0.212 & $0.322^{\mathrm{a}}$ & 0.070 \\
MMSE & -0.079 & -0.208 & -0.100 & 1.000 \\
\hline
\end{tabular}

Numbers are Spearman correlation coefficients $\left(r_{s}\right) .{ }^{a} p<0.05$; ${ }^{b} p<0.005$. Abbreviations: CSF cerebrospinal fluid, IGF insulin growth factor, IGFBP insulin growth factor binding protein, MMSE Mini-Mental State Examination.

When comparing IGFs with WMLs there were no significant correlations between either IGF-I or IGF-II and WMLs (data not shown).

\section{Discussion}

Here we found significantly lower blood plasma levels of IGF-II and IGFBP-3 (the main IGF-binding protein in plasma) in patients with $\mathrm{AD}$. In the CSF of these patients, we also found higher levels of both IGF-II and IGFBP-2 (the main IGF-binding protein in CSF). When adjusting for age, gender and BMI, only levels of IGF-II and IGFBP-3 in blood plasma differed between the two groups, possibly because of significantly lower levels of these two proteins in men with AD. Furthermore, there were significant correlations between components of the IGF-system and tau in healthy controls and between components of the IGF system and P-tau in patients with AD.

There were several limitations of this study. The apolipoprotein $\mathrm{E} \varepsilon 4$ allele is a known risk factor for $\mathrm{AD}$, but was not analyzed for the controls in this material. Nutritional status is known to affect the IGF system [34]. Unfortunately, we only obtained BMI data on a subset of patients with $\mathrm{AD}$ and controls. Also, pre-albumin and albumin, as markers of nutritional status were not analyzed.

We mainly focused on investigating changes in IGF-II levels in blood plasma and CSF in patients with AD. To the best of our knowledge, only one previous study has explored IGF-II levels in the CSF of such patients. In an

Table 4 Correlations between biomarkers in CSF and MMSE in healthy controls

\begin{tabular}{lllll}
\hline & CSF A $\boldsymbol{\beta} 42$ & CSF Tau & CSF P-Tau & MMSE \\
\hline CSF IGF-I & 0.195 & $0.523^{\mathrm{a}}$ & 0.199 & -0.092 \\
CSF IGF-II & -0.113 & $0.414^{\mathrm{a}}$ & 0.155 & -0.111 \\
CSF IGFBP-2 & -0.014 & $0.618^{\mathrm{b}}$ & 0.247 & -0.12 \\
CSF IGFBP-3 & -0.030 & $0.547^{\mathrm{a}}$ & 0.194 & -0.080 \\
MMSE & -0.085 & 0.164 & -0.095 & 1.000 \\
\hline
\end{tabular}

Numbers are Spearman correlation coefficients $\left(r_{s}\right) .{ }^{a} p<0.05 ;{ }^{b} p<0.005$. Abbreviations: CSF cerebrospinal fluid, IGF insulin growth factor, IGFBP insulin growth factor binding protein MMSE Mini-Mental State Examination. analysis of 10 patients and 10 controls, Tham et al. [35] found no difference in CSF levels of IGF-I, while there was a significant elevation of IGF-II in CSF, which is in accordance with our present findings. They also found significantly elevated CSF levels of two binding proteins, which they believed to be IGFBP-2 and IGFBP-6, in part matching our result.

The existing literature on changes in CSF or plasma levels of IGF-I in patients with AD is divergent and often contradictory $[17,36,37]$. In a large multicentre study, Duron et al. found significantly lower levels of IGF-I and IGFBP-3 in the blood plasma of male patients with $\mathrm{AD}$ [38]. We found similar results for the IGFBP-3 level in blood plasma. On the other hand, whereas Johansson et al. found elevated levels of IGF-I in serum, they also found significantly higher serum levels of IGFBP-3 [12].

Much effort has been invested in developing treatment strategies targeting the hypothetically skewed nature of amyloid homeostasis-most notably immunomodulatory therapies aimed at increasing the clearance of $A \beta 42$. To date, this approach has not been able to limit the progress of the disease, even though the $A \beta 42$ burden of the brain has been shown to diminish [39]. Perhaps these treatment studies have been performed with patients too far along in the course of the disease, which might explain the discouraging results. However, another possibility is that other pathological mechanisms, in addition to the accumulation of $\beta$-amyloid, are important for individuals affected by sporadic AD. For example, an ineffective IGF system that fails to uphold the neuroregenerative and neuroprotective mechanisms necessary for a healthy brain, might contribute to the pathological changes seen in patients with AD. This could be caused by decreased levels of active IGFs [19], or by errors elsewhere in the signaling pathway from the cell receptor to the cell nucleus [40]. The latter would be equivalent to a decreased sensitivity of the brain to IGFs, analogous to an increased insulin resistance. Indeed, insulin and IGF share a high degree of structural and functional homology and each of them bind to-and activate-the receptor of the other molecule [41,42]. An increased insulin resistance of the brain has been implied to play a role in AD [5,21]. Thus, Talbot et al. demonstrated elegantly that patients with AD show a markedly reduced response to insulin in the hippocampus and the cerebellar cortex, accompanied by a greatly reduced response to IGF-I as well. The magnitude of these changes increased progressively, from cognitively normal cases, through patients with mild cognitive impairment, to patients with full-blown $\mathrm{AD}$, regardless of the incidence of diabetes [43]. We found the levels of IGF-II in CSF to be significantly higher in patients with $\mathrm{AD}$, as would be expected if there indeed were an increased resistance to IGFs, thus supporting this hypothesis. 
Faulty IGF-binding proteins could also play a role in the development of AD. An over-expression of IGFBP-2 has been shown to reduce postnatal growth in mice, most likely by inhibiting IGF [44]. Our data showed an increase of IGFBP-2 in both plasma and CSF, which might diminish the bioactivity of IGF.

A third possibility could be that the changes in the IGF system is not at all a part of the disease process in patients with $\mathrm{AD}$, but rather a part of the body's defense against brain damage. Both IGF-I and IGF-II seem to protect against intrinsic and extrinsic cell death stimuli [45]. Thus, inducing traumatic brain damage in mice provoked a brief induction of IGF-I expression and its associated signalling components in the acute posttraumatic period [46]. Also, administration of IGF-I to brain-damaged rats seemed to ameliorate neurobehavioural dysfunction [47]. In humans, increasing circulating levels of IGF-I by adminestering GH, seemed to improve disabilities after traumatic brain damage, including improved cognitive functions [48]. In the present study the levels of tau-an established marker for neuronal damage [49]-correlated positively with the levels of IGF-I, IGF-II, IGFBP-2 and IGFBP-3 in healthy controls, suggesting that the levels of these IGF system components may indeed increase with neuronal damage-possibly as a neuroprotective response.

In $\mathrm{AD}$, levels of P-tau are generally increased when compared to healthy controls, as a result of the higher phosphorylated state of tau in the brain, with more NTFs [50]. The NTF burden of the brain has in turn been shown to correlate with the degree of neuronal loss in $\mathrm{AD}$ [51]. In the present study, the levels of P-tau in patients with $\mathrm{AD}$ were positively correlated with those of IGF-I, IGFBP-2 and IGFBP-3, albeit with correlation coefficients less than 0.4. This suggests an association between levels of IGF system components and P-tau, which supports the theory that the levels of the IGF system components increase as a response to neuronal damage also in AD.

\section{Conclusions}

In conclusion, we found changes in the IGF-related system in patients with $\mathrm{AD}$, including altered levels of IGFII in CSF and blood plasma. There were also significant correlations between IGF system components and established biomarkers for AD in the CSF. However, further investigations are necessary to unravel the mechanisms behind the altered IGF-II levels in patients with $\mathrm{AD}$, which might provide important clues to the nature of $\mathrm{AD}$, as well as potential new treatment strategies.

\section{Competing interests}

The authors declare that they have no competing interests.

\section{Authors' contributions}

$\mathrm{JH}$ participated in the study design, performed the statistical analyses and drafted the manuscript. $\mathrm{OH}$ participated in the study design and the statistical analyses and critically revised the manuscript. Both KN and LM made major contributions to the acquisition of data and have critically revised the manuscript. All authors have given final approval of the version to be published.

\section{Acknowledgements}

The study was supported by the Swedish Research Council, The Crafoord Foundation, The Swedish Brain Foundation, the Skåne University Hospital Foundation, the Johan and Jakob Söderbergs Foundation, the Swedish Alzheimer Association, and the Swedish federal government under the LUA/ALF agreement.

Received: 7 January 2014 Accepted: 28 March 2014 Published: 1 April 2014

\section{References}

1. Sicras A, Rejas J, Arco S, Flores E, Ortega G, Esparcia A, Suárez A, Gordillo MJ: Prevalence, resource utilization and costs of vascular dementia compared to Alzheimer's dementia in a population setting. Dement Geriatr Cogn Disord 2005, 19(5-6):305-315.

2. Puglielli L: Aging of the brain, neurotrophin signaling, and Alzheimer's disease: is IGF1-R the common culprit? Neurobiol Aging 2008, 29:795-811.

3. Zetterberg $\mathrm{H}$, Blennow $\mathrm{K}$, Hanse E: Amyloid beta and APP as biomarkers for Alzheimer's disease. Exp Gerontol 2010, 45(1):23-29.

4. D'Ercole AJ, Ye P, Calikoglu AS, Gutierrez-Ospina G: The role of the insulin-like growth factors in the central nervous system. Mol Neurobiol 1996, 13:227-255.

5. de la Monte SM: Insulin resistance and Alzheimer's disease. BMB Rep 2009, 42(8):475-481.

6. Russo VC, Gluckman PD, Feldman EL, Werther GA: The insulin-like growth factor system and its pleiotropic functions in brain. Endoc Rev 2005, 26:916-943.

7. Chen DY, Stern SA, Garcia-Osta A, Saunier-Rebori B, Pollonini G, Bambah-Mukku D, Blitzer RD, Alberini CM: A critical role for IGF-II in memory consolidation and enhancement. Nature 2011, 469:491-497.

8. Feldman EL, Sullivan KA, Kim B, Russell JW: Insulin-like growth factors regulate neuronal differentiation and survival. Neurobiol Dis 1997, 4(3-4):201-214.

9. Hawkes C, Kar S: The insulin-like growth factor-II/mannose-6-phosphate receptor: structure, distribution and function in the central nervous system. Brain Res Rev 2004, 44:117-140.

10. Alberini CM, Chen DY: Memory enhancement: consolidation, reconsolidation and insulin-like growth factor 2. Trends Neurosci 2012, 35:274-283

11. Lee $W H$, Michels KM, Bondy CA: Localization of insulin-like growth factor binding protein-2 messenger RNA during postnatal brain development: correlation with insulin-like growth factors I and II. NSC 1993, 53:251-265.

12. Johansson P, Åberg D, Johansson J-O, Mattsson N, Hansson O, Ahrén B, Isgaard J, Åberg ND, Blennow K, Zetterberg H, Wallin A, Svensson J: Serum but not cerebrospinal fluid levels of insulin-like growth factor-I (IGF-I) and IGF-binding protein-3 (IGFBP-3) are increased in Alzheimer's disease. Psychoneuroendocrinology 2013, 38:1729-1737.

13. Firth SM, Baxter RC: Cellular actions of the insulin-like growth factor binding proteins. Endocr Rev 2002, 23:824-854.

14. Burke SN, Barnes CA: Neural plasticity in the ageing brain. Nat Rev Neurosci 2006, 7:30-40.

15. Garcia-Fernandez M, Sierra I, Puche JE, Guerra L, Castilla-Cortazar I: Liver mitochondrial dysfunction is reverted by insulin-like growth factor II (IGF-II) in aging rats. J Trans/ Med 2011, 9:123.

16. van Dam PS, Aleman A: Insulin-like growth factor-l, cognition and brain aging. Eur J Pharmacol 2004, 490:87-95.

17. Watanabe T, Miyazaki A, Katagiri T, Yamamoto H, Idei T, Iguchi T: Relationship between serum insulin-like growth factor-1 levels and Alzheimer's disease and vascular dementia. J Am Geriatr Soc 2005, 53:1748-1753.

18. van Dam PS, Aleman A, de Vries WR, Deijen JB, van der Veen EA, de Haan EH, Koppeschaar HP: Growth hormone, insulin-like growth factor I and cognitive function in adults. Growth Horm IGF Res 2000, 10(Suppl B):S69-S73. 
19. Aleman A, Torres-Alemán I: Circulating insulin-like growth factor I and cognitive function: neuromodulation throughout the lifespan. Prog Neurobiol 2009, 89:256-265

20. Rivera EJ, Goldin A, Fulmer N, Tavares R, Wands JR, de la Monte SM: Insulin and insulin-like growth factor expression and function deteriorate with progression of Alzheimer's disease: link to brain reductions in acetylcholine. J Alzheimers Dis 2005, 8:247-268.

21. Steen E, Terry BM, Rivera EJ, Cannon JL, Neely TR, Tavares R, Xu XJ, Wands $J R$, de la Monte SM: Impaired insulin and insulin-like growth factor expression and signaling mechanisms in Alzheimer's disease-is this type 3 diabetes? J Alzheimers Dis 2005, 7:63-80

22. Kita Y, Ago Y, Takano E, Fukada A, Takuma K, Matsuda T: Galantamine increases hippocampal insulin-like growth factor 2 expression via a7 nicotinic acetylcholine receptors in mice. Psychopharmacology (Berl) 2013, 225:543-551.

23. Cohen E, Paulsson JF, Blinder P, Burstyn-Cohen T, Du D, Estepa G, Adame A, Pham HM, Holzenberger M, Kelly JW, Masliah E, Dillin A: Reduced IGF-1 signaling delays age-associated proteotoxicity in mice. Cell 2009, 139:1157-1169.

24. Freude S, Hettich MM, Schumann C, Stöhr O, Koch L, Köhler C, Udelhoven M, Leeser U, Müller M, Kubota N, Kadowaki T, Krone W, Schröder H, Brüning JC, Schubert M: Neuronal IGF-1 resistance reduces Abeta accumulation and protects against premature death in a model of Alzheimer's disease. FASEB J 2009, 23:3315-3324.

25. Carro E, Trejo JL, Gomez-Isla T, LeRoith D, Torres-Aleman I: Serum insulin-like growth factor I regulates brain amyloid-beta levels. Nat Med 2002, 8:1390-1397.

26. Pan W, Kastin AJ: Interactions of IGF-1 with the blood-brain barrier in vivo and in situ. Neuroendocrinology 2000, 72:171-178.

27. Niikura T, Hashimoto Y, Okamoto T, Abe Y, Yasukawa T, Kawasumi M, Hirak T, Kita Y, Terashita K, Kouyama K, Nishimoto I: Insulin-like growth factor I (IGF-I) protects cells from apoptosis by Alzheimer's V642I mutant amyloid precursor protein through IGF-I receptor in an IGF-binding protein-sensitive manner. J Neurosci 2001, 21:1902-1910.

28. Doré S, Kar S, Quirion R: Insulin-like growth factor I protects and rescues hippocampal neurons against beta-amyloid- and human amylin-induced toxicity. Proc Natl Acad Sci USA 1997, 94:4772-4777.

29. American Psychiatric Association: Diagnostic and Statistical Manual of Mental Disorders: DSM-III-R. Arlington: American Psychiatric Association; 1987.

30. McKhann G, Drachman D, Folstein M, Katzman R, Price D, Stadlan EM: Clinical diagnosis of Alzheimer's disease: report of the NINCDS-ADRDA Work Group under the auspices of Department of Health and Human Services Task Force on Alzheimer's Disease. Neurology 1984, 34:939-944.

31. Wahlund LO, Barkhof F, Fazekas F, Bronge L, Augustin M, Sjögren M, Wallin A, Ader H, Leys D, Pantoni L, Pasquier F, Erkinjuntti T, Scheltens P, European Task Force on Age-Related White Matter Changes: A new rating scale for age-related white matter changes applicable to MRI and CT. Stroke 2001, 32:1318-1322

32. Blennow K, Hampel H, Weiner M, Zetterberg H: Cerebrospinal fluid and plasma biomarkers in Alzheimer disease. Nat Rev Neurol 2010, 6:131-144.

33. Hertze J, Minthon L, Zetterberg H, Vanmechelen E, Blennow K, Hansson O: Evaluation of CSF biomarkers as predictors of Alzheimer's disease: a clinical follow-up study of 4.7 years. J Alzheimers Dis 2010, 21:1119-1128.

34. Thissen JP, Underwood LE, Ketelslegers JM: Regulation of insulin-like growth factor-I in starvation and injury. Nutr Rev 1999, 57:167-176.

35. Tham A, Nordberg A, Grissom FE, Carlsson-Skwirut C, Viitanen M, Sara VR: Insulin-like growth factors and insulin-like growth factor binding proteins in cerebrospinal fluid and serum of patients with dementia of the Alzheimer type. J Neural Transm Gen Sect 1993, 5:165-176.

36. Salehi Z, Mashayekhi F, Naji M: Insulin like growth factor-1 and insulin like growth factor binding proteins in the cerebrospinal fluid and serum from patients with Alzheimer's disease. Biofactors 2008, 33:99-106.

37. Vardy ERLC, Rice PJ, Bowie PCW, Holmes JD, Grant PJ, Hooper NM: Increased circulating insulin-like growth factor-1 in late-onset Alzheimer's disease. J Alzheimers Dis 2007, 12:285-290.

38. Duron E, Funalot B, Brunel N, Coste J, Quinquis L, Viollet C, Belmin J, Jouanny P, Pasquier F, Treluyer J-M, Epelbaum J, Le Bouc Y, Hanon O: Insulin-like growth factor-I and insulin-like growth factor binding protein-3 in Alzheimer's disease. J Clin Endocrinol Metab 2012, 97:4673-4681.
39. Delrieu J, Ousset P-J, Caillaud C, Vellas B: 'Clinical trials in Alzheimer's disease': immunotherapy approaches. J Neurochem 2012, 120(Suppl 1):186-193.

40. Moloney AM, Griffin RJ, Timmons S, O'Connor R, Ravid R, O'Neill C: Defects in IGF-1 receptor, insulin receptor and IRS-1/2 in Alzheimer's disease indicate possible resistance to IGF-1 and insulin signalling. Neurobio/ Aging 2010, 31:224-243.

41. Gasparini $\mathrm{L}, \mathrm{Xu} \mathrm{H}$ : Potential roles of insulin and IGF-1 in Alzheimer's disease. Trends Neurosci 2003, 26:404-406

42. de la Monte SM, Wands JR: Review of insulin and insulin-like growth factor expression, signaling, and malfunction in the central nervous system: relevance to Alzheimer's disease. J Alzheimers Dis 2005, 7:45-61.

43. Talbot $\mathrm{K}$, Wang H-Y, Kazi H, Han L-Y, Bakshi KP, Stucky A, Fuino RL, Kawaguchi KR, Samoyedny AJ, Wilson RS, Arvanitakis Z, Schneider JA, Wolf BA, Bennett DA, Trojanowski JQ, Arnold SE: Demonstrated brain insulin resistance in Alzheimer's disease patients is associated with IGF-1 resistance, IRS-1 dysregulation, and cognitive decline. J Clin Invest 2012, 122:1316-1338.

44. Hoeflich A, Wu M, Mohan S, Föll J, Wanke R, Froehlich T, Arnold GJ, Lahm H, Kolb HJ, Wolf E: Overexpression of insulin-like growth factor-binding protein-2 in transgenic mice reduces postnatal body weight gain. Endocrinology 1999, 140:5488-5496.

45. Kurmasheva RT, Houghton PJ: IGF-I mediated survival pathways in normal and malignant cells. Biochim Biophys Acta 2006, 1766:1-22

46. Madathil SK, Evans HN, Saatman KE: Temporal and regional changes in IGF-1/IGF-1R signaling in the mouse brain after traumatic brain injury. J Neurotrauma 2010, 27:95-107.

47. Saatman KE, Contreras PC, Smith DH, Raghupathi R, McDermott KL, Fernandez SC, Sanderson KL, Voddi M, McIntosh TK: Insulin-like growth factor-1 (IGF-1) improves both neurological motor and cognitive outcome following experimental brain injury. Exp Neurol 1997 147:418-427.

48. Devesa J, Reimunde P, Devesa P, Barberá M, Arce V: Growth hormone (GH) and brain trauma. Horm Behav 2013, 63:331-344.

49. Blennow K, Hampel H: CSF markers for incipient Alzheimer's disease. Lancet Neurol 2003, 2:605-613.

50. Buerger K, Ewers M, Pirttilä T, Zinkowski R, Alafuzoff I, Teipel SJ, DeBernardis J, Kerkman D, McCulloch C, Soininen H, Hampel H: CSF phosphorylated tau protein correlates with neocortical neurofibrillary pathology in Alzheimer's disease. Brain 2006, 129:3035-3041.

51. Gómez-Isla T, Hollister R, West H, Mui S, Growdon JH, Petersen RC, Parisi JE, Hyman BT: Neuronal loss correlates with but exceeds neurofibrillary tangles in Alzheimer's disease. Ann Neurol 1997, 41:17-24

doi:10.1186/1471-2377-14-64

Cite this article as: Hertze et al:: Changes in cerebrospinal fluid and blood plasma levels of IGF-II and its binding proteins in Alzheimer's disease: an observational study. BMC Neurology 2014 14:64.

\section{Submit your next manuscript to BioMed Central and take full advantage of:}

- Convenient online submission

- Thorough peer review

- No space constraints or color figure charges

- Immediate publication on acceptance

- Inclusion in PubMed, CAS, Scopus and Google Scholar

- Research which is freely available for redistribution 